\title{
Identification of Factors Affecting Pedestrian Satisfaction toward Land Use and Street Type
}

\author{
Soongbong Lee ${ }^{1}$, Myungjoo Han ${ }^{2}$, Kyoungah Rhee ${ }^{3}$ and Bumjoon Bae ${ }^{4, *(\mathbb{D}}$ \\ 1 Big Data Platform and Data Economy, The Korea Transport Institute, 370 Sicheong-daero, \\ Sejong 30147, Korea; habanera82@koti.re.kr \\ 2 Gyeonggi Public Investment Management Center, Gyeonggi Research Institute, Suwon City 16207, Korea; \\ mjhan@gri.re.kr \\ 3 Naeil Engineering \& Consultants, Anyang 14056, Korea; karhee0512@gmail.com \\ 4 Center for Privately-Financed Highway Studies, The Korea Transport Institute, 370 Sicheong-daero, \\ Sejong 30147, Korea \\ * Correspondence: bbae2016@koti.re.kr
}

Citation: Lee, S.; Han, M.; Rhee, K.; Bae, B. Identification of Factors Affecting Pedestrian Satisfaction toward Land Use and Street Type. Sustainability 2021, 13, 10725. https:// doi.org/10.3390/su131910725

Academic Editor: Armando Cartenì

Received: 6 September 2021

Accepted: 24 September 2021

Published: 27 September 2021

Publisher's Note: MDPI stays neutral with regard to jurisdictional claims in published maps and institutional affiliations.

Copyright: (c) 2021 by the authors. Licensee MDPI, Basel, Switzerland. This article is an open access article distributed under the terms and conditions of the Creative Commons Attribution (CC BY) license (https:// creativecommons.org/licenses/by/ $4.0 /)$.

\begin{abstract}
Walking is an essential sustainable mode of transportation. Encouraging to increase walking trips can bring various social and economic benefits to our society. Since the policy paradigm has been shifting from car-oriented to pedestrian-oriented, interest in securing pedestrian rights and improving walking environments is increasing significantly. This study aims to examine factors affecting pedestrian satisfaction according to land use and street type. A pedestrian satisfaction survey was conducted in an industrial city with a mid-size population in the city of Changwon, South Korea. Based on the survey data from 500 respondents, factors affecting pedestrian satisfaction were analyzed by land use (commercial or residential areas) and street type (non-separated or separated sidewalks). The analysis results, using binary and ordered logit models, showed that the less illegal parking, the more pedestrian space, pedestrian guidance facility, and green space, the higher the pedestrian satisfaction. Factors positively affecting the satisfaction of pedestrian paths according to land use were physical environmental variables, such as the separated sidewalk variable. In commercial areas, pedestrian guidance facilities and street cleanliness were included as major influencing factors, implying differences in land use influencing factors. A common factor affecting the satisfaction of separated or non-separated sidewalk cases was also identified as the sufficiency of walking space. Therefore, the most urgent policy measure for improving pedestrian satisfaction for the city was to install a sidewalk or expand the pedestrian space. In the pedestrian-vehicle separation models, green space and cleanliness were included as significant variables, and in the non-separated models, variables of pedestrian guidance facilities and sidewalk conditions were included.
\end{abstract}

Keywords: pedestrian satisfaction; logit model; land use; walking environment; Changwon; South Korea

\section{Introduction}

Walking is an essential transportation mode. If appropriately designed to facilitate pedestrian transportation, pedestrian facilities or relevant policies make pedestrian experiences more attractive. Through a modal shift from motorized transportation modes to walking, it is evaluated that various social and economic benefits occur, including vehicle operation costs reduction, traffic accidents reduction, environmental costs reduction, parking costs reduction, and physical health improvement [1,2]. Besides such specific socioeconomic benefits, walking is the most sustainable and advantageous mobility solution to cope with climate change [3]. Therefore, the policy paradigm has been shifting from car-oriented policies to people- and pedestrian-oriented policies, and pedestrian-related laws, systems, and projects are actively underway as part of national policies such as low-carbon and green growth. 
In order to stimulate pedestrian transportation, it is crucial to increase the pedestrian satisfaction of the citizens first. Therefore, to design and establish a pedestrian-related policy, it is necessary first to identify the factors affecting the pedestrian satisfaction of local citizens.

In general, pedestrian satisfaction can be classified into pedestrian safety, walking convenience, and comfort. Such satisfaction attributes can be evaluated by a variety of indicators of the presence of sidewalks, illegal parking, the sufficiency of walking space, cleanliness, and so on. On the other hand, it is expected that factors affecting pedestrian satisfaction will differ depending on why and where people walk. For example, the importance of pedestrian environment factors affecting pedestrian satisfaction may differ depending on travel purpose, such as commuting, school, business, shopping, and leisure. In addition, pedestrian environment evaluation indicators, considered according to the types of pedestrian spaces such as new towns, old downtown, commercial areas, pedestrian paths near stations, and rivers, or differences in land use, such as residential and commercial areas, are different.

As pointed out by Sahani and Bhuyan [4], pedestrian satisfaction involves different facets, i.e., the physical conditions of walking environmental elements and satisfaction level for walking experiences while using them. Many studies dealt with such physical conditions or design elements of the facilities assessed the walkability of various cities worldwide [5-11]. Walkability represents the suitability of an urban environment to provide pedestrian walkways or such environmental features themselves that make it useful, safe, comfortable, and attractive for walking [10,12,13]. Blečić, Cecchini [10] show that walkability can be incorporated as a relevant factor in analyzing the urban peripheralization process characterized by spatial and social inequalities. Improving walkability leads to increasing urban accessibility and travel equity because walking is socially equitable, i.e., it is available to most people non-discriminately [14]. According to Distefano, Pulvirenti [11], and Campisi, Ignaccolo [15], elderly or impaired people put different priorities on the elements of walking environments depending on their physical abilities. Labdaoui, Mazouz [12] propose a comport walkability index using thermal comfort. Forsyth and Southworth [14] provide different definitions of walkability as a short trip distance, a barrier-free traversable walking environment, safety, pedestrian infrastructure, and upscale and pleasant walking conditions. Despite the various aspects of walkability and different definitions used in the literature, several commonalities can be seen, such as presence and continuity of sidewalks, accessibility of facilities to people with different abilities, directness of pedestrian paths, connections to frequent transit services, ease and safety of crossings, visual interest, and perceived or actual security [16]. On the other hand, other studies focused on the satisfaction that is the perceived level of service to the attributes of walkability [3,17-23].

To this end, this study examines factors affecting pedestrian satisfaction according to not only the physical conditions of the walking environment, including land use and street type but also the satisfaction level that pedestrians perceive for the individual attributes of design or operational elements. In the study, a pedestrian satisfaction survey was conducted in the city of Changwon, South Korea, through field investigation and citizen opinion survey. First, two residential and two commercial areas were selected for the survey to examine factors affecting pedestrian satisfaction according to land use and walking space type. Then, walking satisfaction surveys were conducted in the four survey sites through citizen opinion surveys, and quantitative walking environment factors were investigated. Lastly, based on the survey outputs, a logit model was estimated to identify the factors affecting pedestrian satisfaction and verify their differences by land use and walking space type. Figure 1 shows the conceptual framework of the study. 


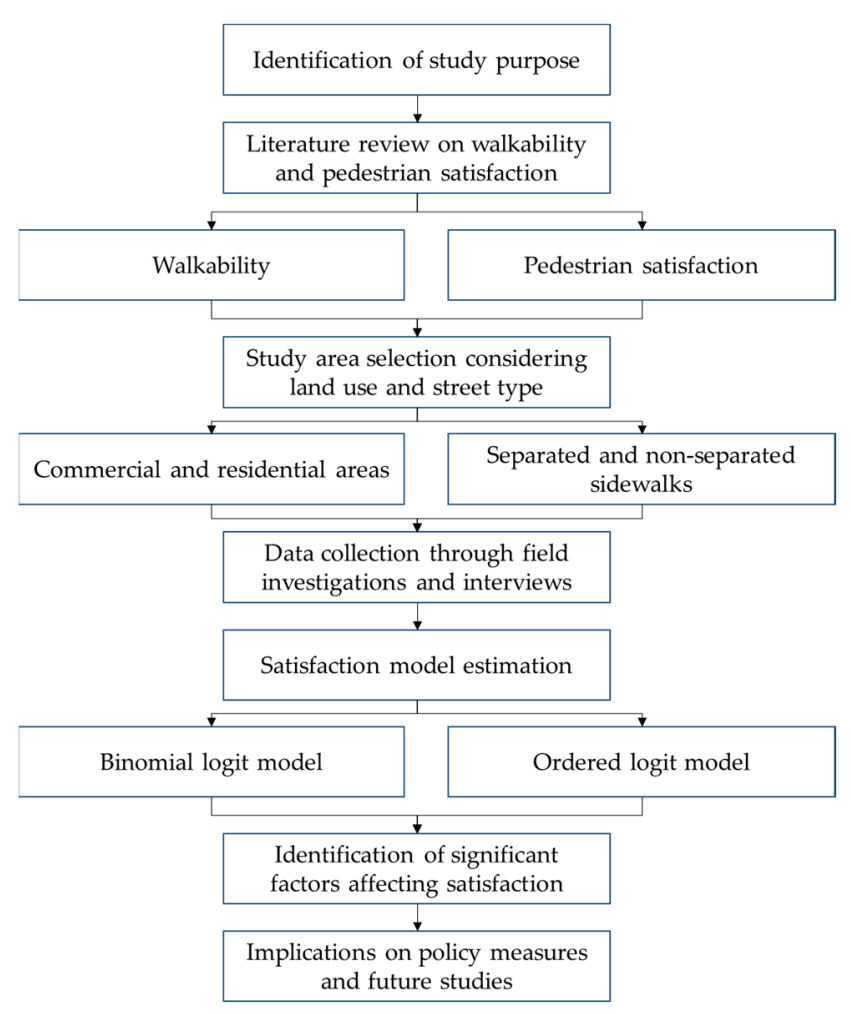

Figure 1. Conceptual framework of the study.

The rest of the paper is structured with a literature review of pedestrian transportation and the data description, modeling results and discussions, and the conclusions for the findings.

\section{Literature Review}

The literature reviewed in this section is two-fold: studies on characteristics of pedestrian transportation and factors affecting pedestrian satisfaction.

Recently, as interest in quality of life and well-being has increased, the paradigm of the transportation sector has been changing from a car-oriented transportation system to an eco-friendly, pedestrian- or people-oriented urban space. Walking is the most basic means of transportation for humans and is the basis of all activities such as commuting, going to school, work, and leisure. In terms of transportation, walking itself is also a form of travel, and it serves as a link between various transportation modes, e.g., buses and subways.

In addition, many studies claim that walking provides various functions other than transportation modes. For example, Oh and Seo [24] argue that the concept of walking in urban design has expanded continuously with the times from the primary means of transportation. Specifically, the perspective of understanding walking has been expanded as a means of experience and recognition of urban space, a means of leisure, performing social functions, and a monitoring function of public space [24]. KOTI [25] emphasizes the eco-friendliness of walking because it relies on human power and has little impact on the environment. In addition, the literature insists that walking plays a role in bringing novelty and vitality to life in outdoor spaces, going beyond transportation. It contributes to revitalizing the economy of a city or community, promotes social exchange and local economic activities, connects transportation modes, guarantees accessibility, and improves human health. As pedestrians, everyone contributes to ensuring equality in their community and enhancing safety and security [25].

In the particular case of South Korea, the recent enactments, such as the Mobility Convenience Promotion Act for the Transportation Vulnerable in 2006 and the Sustainable Transportation and Logistics Development Act in 2009, laid the institutional basis to 
vitalize pedestrian transportation that is a non-motorized, carbon-free transportation mode to reduce congestion and greenhouse gas emissions. Furthermore, since the enactment of the Act on Pedestrian Safety and Convenience Promotion in 2015, interest in securing pedestrian rights and the pedestrian environment has increased significantly.

Along with the pedestrian-oriented policy paradigm shift, research to evaluate and analyze pedestrian satisfaction has actively been underway. According to Ji and Gu [17], the factors of the walking environment that affect pedestrian satisfaction are identified as safety, security, scenery, comfort, and convenience. A case study investigating the pedestrian satisfaction of traditional markets in Korea classified the influential factors into safety, comfort, convenience, and interest [26]. Besides safety, convenience, and comfort, other studies suggested street environments, e.g., air quality, noise, natural shade, planting, or street continuity and visibility as evaluation or design elements $[18,27,28]$.

Based on the common walkability metrics and attributes from the literature and consideration of the built environment of urban design of the country, this study categorizes factors affecting pedestrian satisfaction into safety, convenience, and comfort to examine differences in satisfaction by land use and street type. The characteristics of each influencing factor were set as follows:

- Safety: the presence of sidewalks, illegal parking, perceived safety level from traffic accidents, illegally placed objects, vehicle travel speed, etc. [1,4,11,12,16,18,20-23,26,27,29,30].

- Convenience: sufficiency of pedestrian guidance facilities, sidewalk material (pavement condition), sidewalk slope, easiness to access public transportation facilities, etc. $[4,11,12,16,18,20,22,23,26,27,30]$.

- Comfort: pedestrian volume, the sufficiency of green space, cleanliness, noise level, etc. $[1,4,16,18,21,23,26,27,29,30]$.

\section{Data}

The purpose of this study is to identify factors affecting pedestrian satisfaction by classifying the survey target sites by land use (commercial and residential areas) and street type (streets with separated and non-separated sidewalks). The study areas are located in Changwon, the capital city of Gyeongsangnam-do, a province in the southeast of South Korea (see Figure 2e). The population of the city in 2018 was approximately 1.1 million. The city's demographic characteristics are very similar to those of the whole country. For example, the elderly population aged over 65 and the gender ratio were $13 \%$ and $102 \%$ for Changwon, corresponding 14\% and 100\%, respectively for South Korea. Among the major commercial areas of Changwon City, areas with high pedestrian volume were considered target areas, accounting for whether sidewalks are separated and whether illegal parking is frequent. The residential areas were also selected based on the same criteria for the commercial areas. To this end, four areas were selected as in Table 1 and Figure 2.

Table 1. Features of selected study areas.

\begin{tabular}{ccccc}
\hline Study Area & Street Name & Land Use & Sidewalk & Illegal Parking \\
\hline (A) & Hapsungyet-gil & commercial & Non-separated & $\mathrm{O}$ \\
(B) & Madimi-ro & commercial & Separated & $\mathrm{X}$ \\
(C) & Gyobangdong1-gil & residential & Non-separated & $\mathrm{O}$ \\
(D) & Myungseo-ro & residential & Separated & $\mathrm{X}$ \\
\hline
\end{tabular}




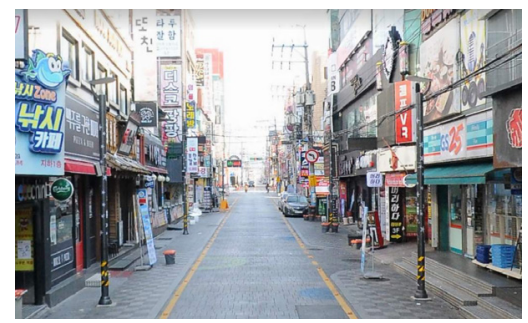

(a) Hapsungyet-gil

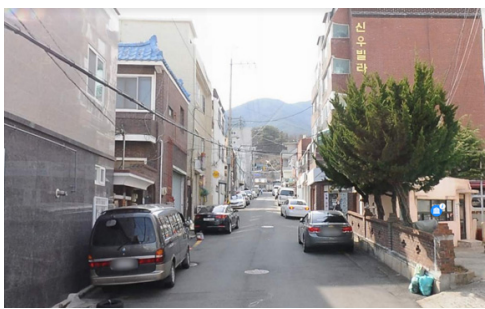

(c) Gyobangdong1-gil

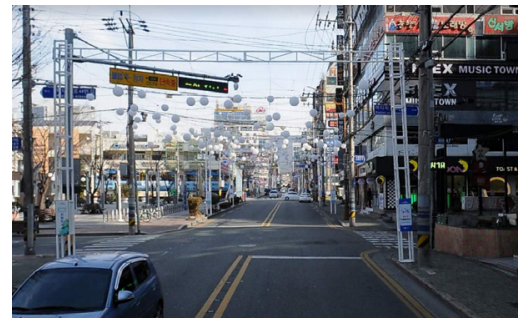

(b) Madimi-ro

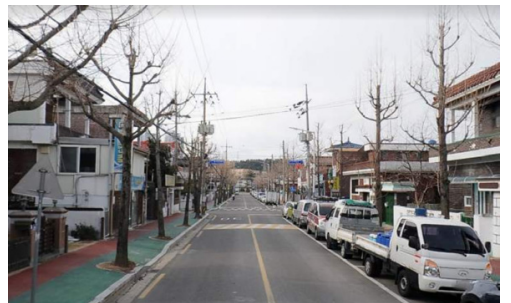

(d) Myungseo-ro

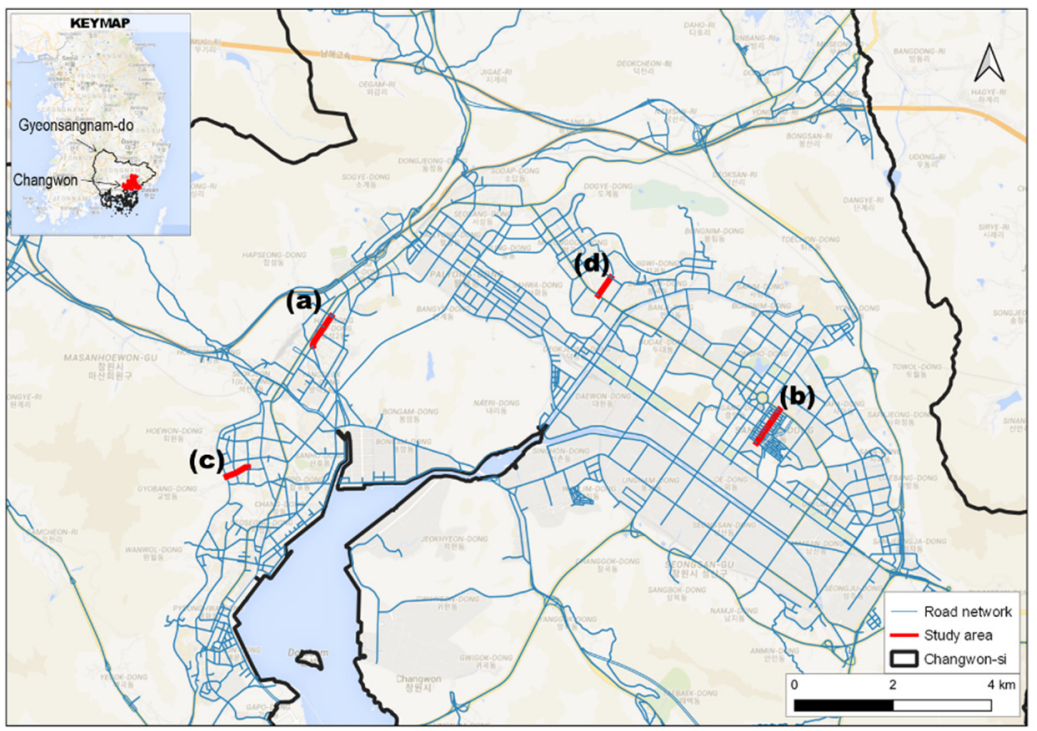

(e) Geolocation of the study areas

Figure 2. Selected study area: (a) Commercial area with non-separated sidewalk; (b) Commercial area with separated sidewalk; (c) Residential area with non-separated sidewalk; (d) Residential area with separated sidewalk (source: https: / / map.kakao.com, accessed on 3 September 2021); (e) Geolocation of the study area.

The survey's sample size was set at 500 people, 125 people per area, and the subjects were pedestrians on the streets. To collect the data, face-to-face interviews were conducted by experienced and trained interviewers using a structured questionnaire on the four study areas in the city. The survey was carried out mainly during the daytime, i.e., 8 a.m. through 7 p.m. on weekdays between 11 May and 22 May in 2018. The questionnaire consists of usual walking behavior, satisfaction with the walking environment, and socioeconomic characteristics described in Figure 3. First, as for the usual walking behavior, the purpose of walking, type of walking path, average walking time per day, and frequency of walking were investigated. Second, satisfaction with the walking environment was surveyed on a 5-point scale (very unsatisfied, unsatisfied, neutral, satisfied, very satisfied) and was composed of walking safety, convenience, and comfort. Specifically, for pedestrian safety, satisfaction with a total of 10 items, such as sufficient pedestrian space, safety from traffic accidents, illegal parking, vehicle travel speed, and illegally placed objects, was surveyed, 
as well as and satisfaction with overall pedestrian safety. For the pedestrian convenience category, with the overall walking convenience satisfaction, four items were asked. They are the sufficiency of pedestrian guidance facilities, easiness to access to public transportation facilities, and sufficiency of facilities for vulnerable road users. For the walking comfort, satisfaction with six items such as the pedestrian density, sufficiency of green space and shelter space, noise, and cleanliness, was surveyed, as well as the overall walking comfort satisfaction. Lastly, the socioeconomic characteristics of respondents were also collected to identify influential factors of pedestrian satisfaction, including age, gender, occupation, housing type, income level, a primary mode of transportation, traffic accident experience, and so on.

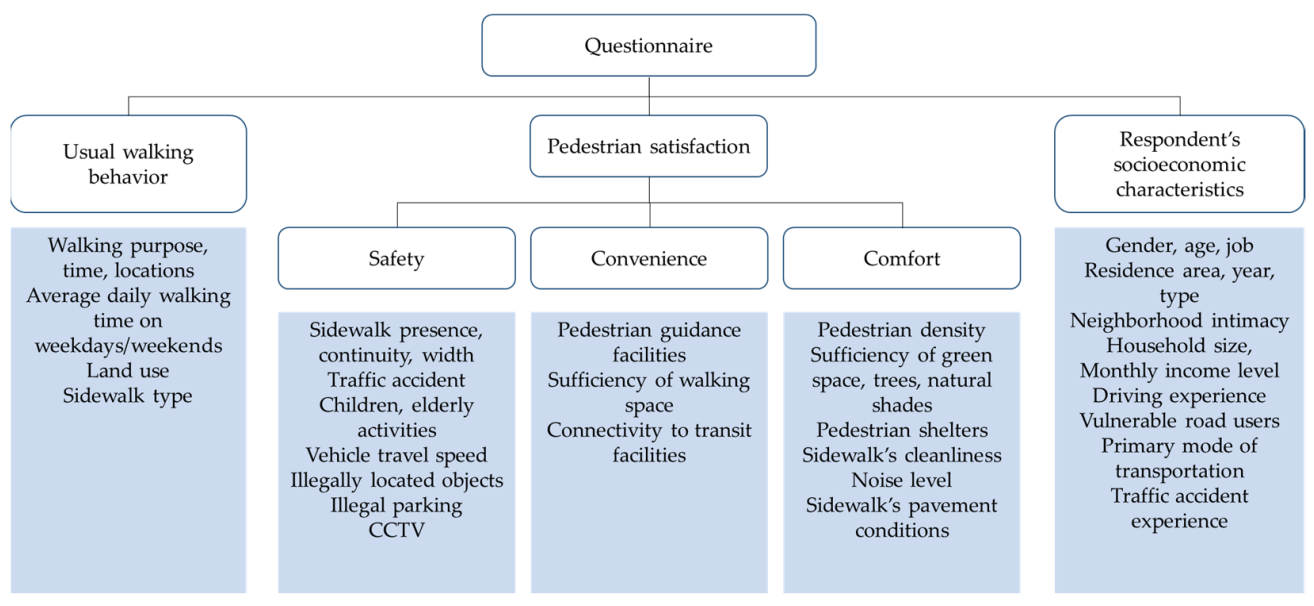

Figure 3. Questionnaire structure for pedestrian satisfaction.

In addition to the survey, field investigations on the subject areas were conducted. Various elements of the physical condition of the pedestrian facilities were examined, including the presence of a separated sidewalk, illegal parking, pedestrian volume, closedcircuit television (CCTV) installation, green or shelter space, cleanliness, and the sidewalk's surface condition.

\section{Modeling Results and Discussion}

This section delineates the modeling approach to identify factors affecting pedestrian satisfaction based on the survey data described in the previous section, then provides and discusses the modeling results.

A total of five logit models were estimated for analyzing pedestrian satisfaction as in Figure 4: a model for the whole sample (S), two models by land use (i.e., commercial and residential areas), and two models for street types (i.e., non-separated sidewalk and separated sidewalk).

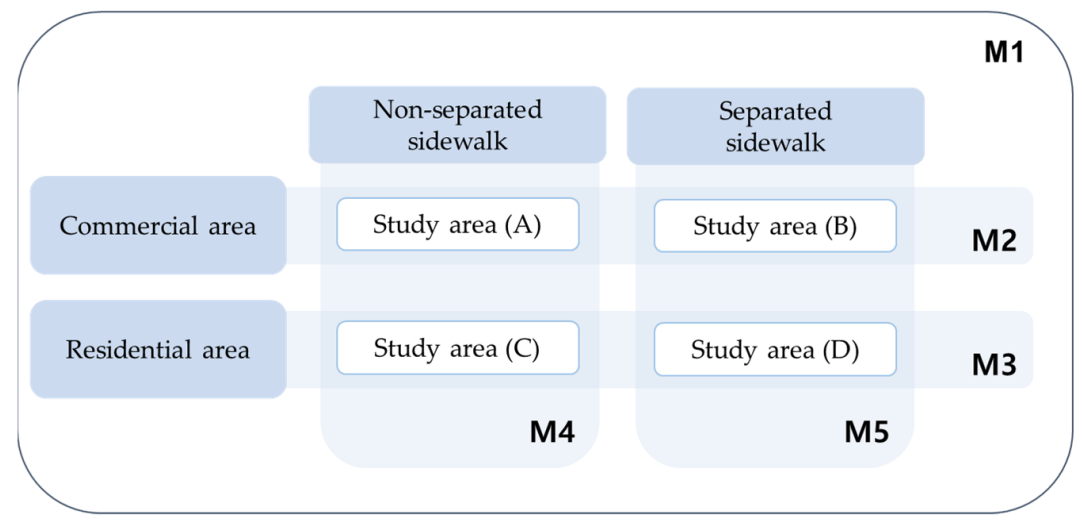

Figure 4. Five pedestrian satisfaction models, i.e., M1-M5. 
For the model type selection, the logit model is more suitable than a linear regression model because the dependent variable of the satisfaction from the survey represents the utility level selected from the respondents, expressed as a non-negative discrete integer. In a logit model analysis where the dependent variable is a nominal scale, e.g., 1 or 0 , the direction of the estimated coefficient is significant rather than the coefficient value itself. Thus, either a binomial logit model or an ordered logit model can be used to identify factors affecting satisfaction. To derive robust results and conclusions, this study used both logit model types for each satisfaction analysis. As depicted in Figure 4, both logit models were estimated and compared for the five different modeling groups. 'M1' refers to the overall satisfaction modeling group in which no distinction of land use or street type is accounted for. 'M2' and 'M3' refer to the satisfaction modeling groups for each land use type, and 'M4' and 'M5' refer to the modeling groups for each street type. To use the binomial logit model with the survey data, the 5-point Likert scale responses must be converted into a binary form, i.e., 'satisfied' and 'not satisfied'. Thus, the 'neutral' responses were classified as 'not satisfied' to derive more conservative policy implications with a critical point of view.

The model selections were made through the backward elimination method. To find significant independent variables that affect the dependent variable, a variable with low statistical significance is removed one-by-one from the model where all the independent variables are entered. To avoid reaching erroneous inference due to multicollinearity among variables, the correlation between the variables was limited to $40 \%$ or less. In addition, the variance inflation factor (VIF) was used to diagnose the multicollinearity issue. A high VIF value indicates high multicollinearity between variables. On the other hand, a low VIF value indicates that low or no multicollinearity exists, making the model more reliable. Twenty-six variables were identified to significantly affect the pedestrian satisfaction models. Table 2 shows the selective descriptive statistics of the survey data. All the variables in Table 2 are in a binary format, except for the dependent variable of 'sat' and independent variable of 'age', which are a 5-point Likert scale and a continuous value, respectively.

Table 3 shows the estimation result of the overall pedestrian satisfaction models (M1). All the estimates included in the models are statistically significant at the $90 \%$ significance level at minimum. For the physical walking environment category, it was found that satisfaction increases when the street, on which a pedestrian frequently walks, is located in a residential area. On the contrary, the satisfaction decreases when illegal parking exists, i.e., pedestrians and vehicles are not segregated. If the walking purpose is commuting to work or school and business trip, the coefficient of the binomial logit model is negative. This implies that, although the walking environment is the same, such compulsory walking trips make pedestrian satisfaction unsatisfied. Other factors having a positive effect on pedestrian satisfaction are sufficient walking space $(x 1)$, pedestrian guidance facilities (x3), and green space (x5), as well as a street slope that does not make pedestrians feel inconvenience (x4). Among the individual characteristics of the respondents, it was found that the more people who had a traffic accident experience (accident), the less satisfied they were and males (gender) are more favorable to walking.

Seven variables with the same coefficient sign were commonly included in both binomial and ordered logit models, including 'landuse' and 'parking'. On the other hand, the walking purpose variable of 'strip1' and the socioeconomic variable of 'gender' were significant only in the binary model. In both models, the null hypothesis that the coefficients are zero is rejected in both models, based on the log-likelihood ratio statistics. In the comparison of the models, the binomial logit model performs better than the ordered logit model because having higher Pseudo $\mathrm{R}^{2}$ and smaller Akaike's Information Criterion (AIC), Bayesian Information Criterion (BIC) values. This result about the model goodness-of-fit is the same for the following modeling groups in Tables 4 and 5. 
Table 2. Descriptive Statistics.

\begin{tabular}{|c|c|c|c|c|c|c|c|}
\hline Category & Variable & Description & Mean & Std. Dev. & Min & $\operatorname{Max}$ & VIF \\
\hline \multirow{2}{*}{ Overall satisfaction } & sat & 5-point Likert scale satisfaction & 2.71 & 0.83 & 1 & 5 & - \\
\hline & sat_2 & $1=$ satisfied, $0=$ otherwise & 0.14 & 0.35 & 0 & 1 & - \\
\hline \multirow{3}{*}{ Physical environment } & sidewalk & $1=$ separated $0=$ non-separated sidewalk & 0.50 & 0.50 & 0 & 1 & 1.50 \\
\hline & landuse & $1=$ frequently walking street is located in a residential area, $0=$ otherwise & 0.44 & 0.50 & 0 & 1 & 1.16 \\
\hline & parking & $1=$ illegal parking, $0=$ otherwise & 0.50 & 0.50 & 0 & 1 & 1.50 \\
\hline \multirow{2}{*}{ Walking purpose } & strip1 & $1=$ commuting, business, school, $0=$ otherwise & 0.56 & 0.50 & 0 & 1 & 2.78 \\
\hline & strip2 & $1=$ shopping , leisure, $0=$ otherwise & 0.30 & 0.46 & 0 & 1 & 2.68 \\
\hline Walking time & walk60 & $1=$ average daily walking time is ranging from 40 to $60 \mathrm{~min}, 0=$ otherwise & 0.23 & 0.42 & 0 & 1 & 1.16 \\
\hline \multirow{7}{*}{ Satisfaction for each attribute } & conv & $1=$ most important factor is convenience, $0=$ otherwise & 0.21 & 0.41 & 0 & 1 & 1.09 \\
\hline & $\mathrm{x} 1$ & $1=$ walking space is sufficient, $0=$ otherwise & 0.12 & 0.32 & 0 & 1 & 1.65 \\
\hline & $\mathrm{x} 2$ & $1=$ safe from traffic accidents, $0=$ otherwise & 0.22 & 0.41 & 0 & 1 & 1.58 \\
\hline & $\mathrm{x} 3$ & $1=$ pedestrian guidance facilities is sufficient, $0=$ otherwise & 0.07 & 0.25 & 0 & 1 & 1.22 \\
\hline & $\mathrm{x} 4$ & $1=$ not bothered about a street slope, $0=$ otherwise & 0.42 & 0.49 & 0 & 1 & 1.29 \\
\hline & $x 5$ & $1=$ green space is sufficient, $0=$ otherwise & 0.13 & 0.34 & 0 & 1 & 1.36 \\
\hline & $x 6$ & $1=$ street is clean, $0=$ otherwise & 0.14 & 0.34 & 0 & 1 & 1.40 \\
\hline \multirow{11}{*}{ Socioeconomic characteristic } & age & respondent's age (continuous) & 41.44 & 16.97 & 13 & 90 & 1.47 \\
\hline & gender & $1=$ male, $0=$ female & 0.38 & 0.49 & 0 & 1 & 1.12 \\
\hline & ht & $1=$ living in an apartment, $0=$ otherwise & 0.41 & 0.49 & 0 & 1 & 1.20 \\
\hline & inc20 & $1=$ monthly household income between $2,000,000$ and 3,000,000 KRW, $0=$ otherwise & 0.18 & 0.39 & 0 & 1 & 1.20 \\
\hline & inc30 & $1=$ monthly household income between $3,000,000$ and $4,000,000 \mathrm{KRW}, 0=$ otherwise & 0.17 & 0.38 & 0 & 1 & 1.21 \\
\hline & inc 40 & $1=$ monthly household income between $4,000,000$ and 5,000,000 KRW, $0=$ otherwise & 0.14 & 0.35 & 0 & 1 & 1.22 \\
\hline & accident & $1=$ experienced traffic accident, $0=$ otherwise & 0.57 & 0.50 & 0 & 1 & 1.14 \\
\hline & neigh & $1=$ feeling neighbors like family, $0=$ otherwise & 0.39 & 0.49 & 0 & 1 & 1.31 \\
\hline & veh & $1=$ primary mode of transportation mode during a typical week is a car, $0=$ otherwise & 0.29 & 0.45 & 0 & 1 & 1.22 \\
\hline & vuser & $1=$ vulnerable road user, $0=$ otherwise & 0.35 & 0.48 & 0 & 1 & 1.39 \\
\hline & year & $1=$ residence period in the city is over 20 years, $0=$ otherwise & 0.23 & 0.42 & 0 & 1 & 1.05 \\
\hline
\end{tabular}


Table 3. Overall Model Estimation Results (M1).

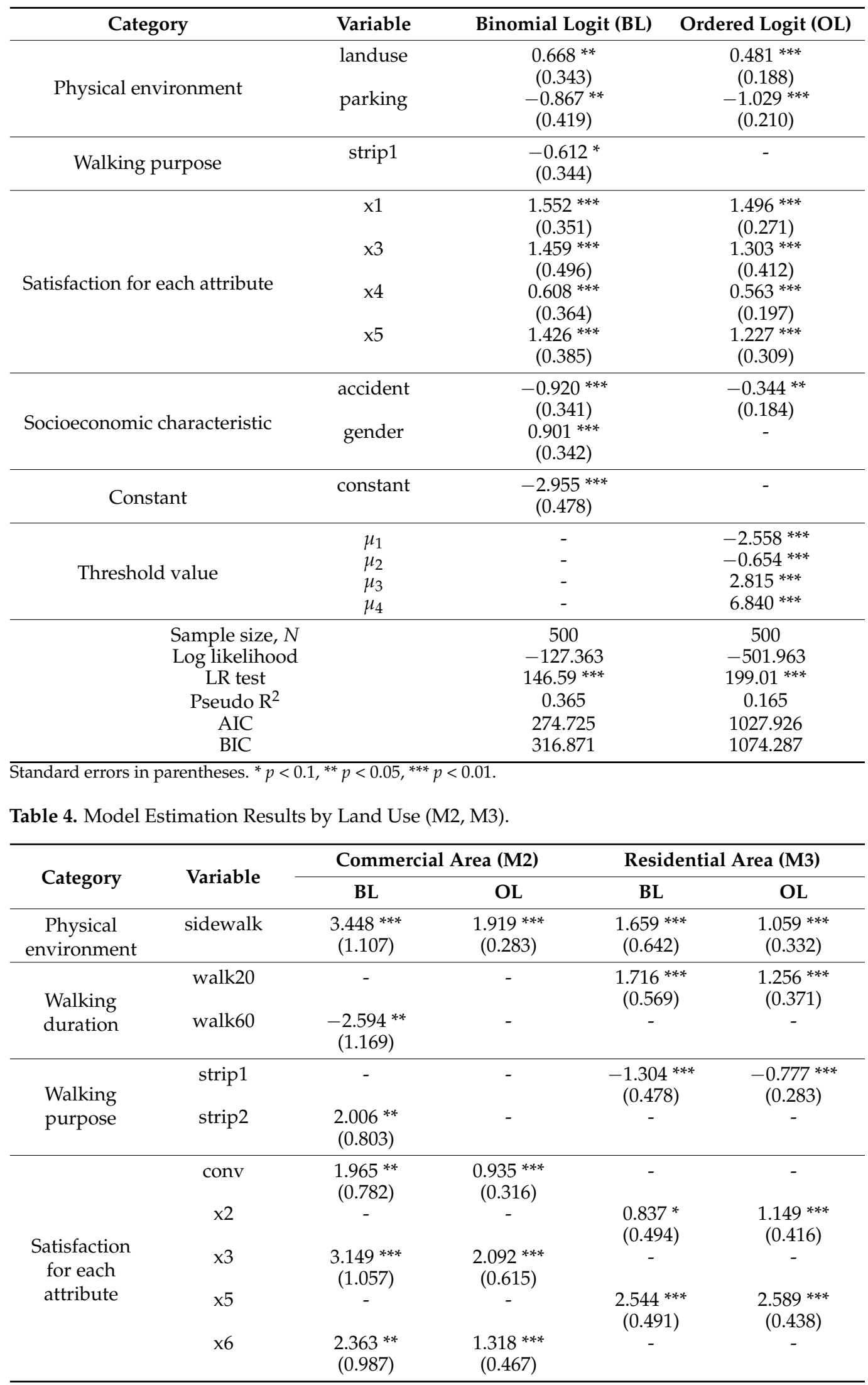


Table 4. Cont.

\begin{tabular}{|c|c|c|c|c|c|}
\hline \multirow{2}{*}{ Category } & \multirow{2}{*}{ Variable } & \multicolumn{2}{|c|}{ Commercial Area (M2) } & \multicolumn{2}{|c|}{ Residential Area (M3) } \\
\hline & & BL & OL & BL & OL \\
\hline \multirow{9}{*}{$\begin{array}{l}\text { Socioeconomic } \\
\text { characteristic }\end{array}$} & gender & $\begin{array}{c}2.506^{* * *} \\
(0.882)\end{array}$ & - & - & - \\
\hline & age & $\begin{array}{l}0.044^{*} \\
(0.025)\end{array}$ & - & - & - \\
\hline & ht & - & - & $\begin{array}{l}1.053^{*} \\
(0.615)\end{array}$ & $\begin{array}{c}0.907^{* * * *} \\
(0.367)\end{array}$ \\
\hline & inc20 & $\begin{array}{l}2.153 * * \\
(1.048)\end{array}$ & - & - & - \\
\hline & inc30 & $\begin{array}{l}2.113^{* *} \\
(1.026)\end{array}$ & - & - & - \\
\hline & inc 40 & - & - & $\begin{array}{l}1.190 * * \\
(0.535)\end{array}$ & - \\
\hline & neigh & $\begin{array}{c}-3.552 * * \\
(1.389)\end{array}$ & - & - & - \\
\hline & veh & $\begin{array}{c}-4.002^{* * *} \\
(1.382)\end{array}$ & $\begin{array}{c}-0.587^{* *} \\
(0.274)\end{array}$ & - & - \\
\hline & year & $\begin{array}{c}2.292^{* * *} \\
(0.851)\end{array}$ & - & - & - \\
\hline Constant & constant & $\begin{array}{c}-10.343^{* * *} \\
(2.246)\end{array}$ & - & $\begin{array}{l}-3.638 \\
(0.666)\end{array}$ & - \\
\hline \multirow{4}{*}{$\begin{array}{c}\text { Threshold } \\
\text { value }\end{array}$} & $\mu_{1}$ & - & $-1.344^{* * *}$ & - & $-2.225^{* * *}$ \\
\hline & $\mu_{2}$ & - & $0.976^{* * *}$ & - & $-0.607^{* * *}$ \\
\hline & $\mu_{3}$ & - & $4.439 * * *$ & - & $3.113^{* * *}$ \\
\hline & $\mu_{4}$ & - & - & - & $7.113^{* * *}$ \\
\hline \multicolumn{2}{|c|}{ Sample size, $N$} & 250 & 250 & 250 & 250 \\
\hline \multirow{2}{*}{\multicolumn{2}{|c|}{$\begin{array}{l}\text { Log likelihood } \\
\text { LR test }\end{array}$}} & -31.732 & -246.955 & -79.312 & -232.255 \\
\hline & & $70.98^{* * *}$ & $91.76^{* * *}$ & $91.58^{* * *}$ & $112.58^{* * *}$ \\
\hline \multicolumn{2}{|c|}{ Pseudo $\mathrm{R}^{2}$} & 0.528 & 0.157 & 0.366 & 0.20 \\
\hline \multicolumn{2}{|c|}{ AIC } & 91.464 & 509.910 & 174.623 & 484.510 \\
\hline \multicolumn{2}{|c|}{ BIC } & 140.765 & 538.082 & 202.795 & 519.725 \\
\hline
\end{tabular}

Standard errors in parentheses. ${ }^{*} p<0.1,{ }^{* *} p<0.05,{ }^{* * *} p<0.01$.

Table 5. Model Estimation Results by Street Type (M4, M5).

\begin{tabular}{|c|c|c|c|c|c|}
\hline \multirow{2}{*}{ Category } & \multirow{2}{*}{ Variable } & \multicolumn{2}{|c|}{ Non-Separated Sidewalk (M4) } & \multicolumn{2}{|c|}{ Separated Sidewalk (M5) } \\
\hline & & BL & OL & BL & OL \\
\hline $\begin{array}{c}\text { Physical } \\
\text { environment }\end{array}$ & parking & - & $\begin{array}{c}0.022 * * * \\
(0.005)\end{array}$ & - & - \\
\hline $\begin{array}{l}\text { Walking } \\
\text { duration }\end{array}$ & walk20 & $\begin{array}{c}2.005 * * \\
(0.834)\end{array}$ & $\begin{array}{c}1.397 * * * \\
(0.363)\end{array}$ & - & - \\
\hline $\begin{array}{l}\text { Walking } \\
\text { purpose }\end{array}$ & strip1 & - & - & $\begin{array}{c}-0.896 * * \\
(0.371)\end{array}$ & - \\
\hline \multirow{5}{*}{$\begin{array}{l}\text { Satisfaction } \\
\text { for each } \\
\text { attribute }\end{array}$} & $\mathrm{x} 1$ & $\begin{array}{c}2.731^{* * *} \\
(0.972)\end{array}$ & $\begin{array}{c}1.794^{* * *} \\
(0.652)\end{array}$ & $\begin{array}{c}1.371^{* * *} \\
(0.371)\end{array}$ & $\begin{array}{c}1.568^{* * *} \\
(0.316)\end{array}$ \\
\hline & $\mathrm{x} 3$ & $\begin{array}{c}5.088^{* * *} \\
(1.608)\end{array}$ & $\begin{array}{c}4.116^{* * *} \\
(0.982)\end{array}$ & - & - \\
\hline & $x 5$ & - & - & $\begin{array}{c}1.290^{* * *} \\
(0.385)\end{array}$ & $\begin{array}{c}1.259 * * * \\
(0.351)\end{array}$ \\
\hline & $x 6$ & - & - & $\begin{array}{c}1.514^{* * *} \\
(0.387)\end{array}$ & $\begin{array}{c}1.805^{* * * *} \\
(0.361)\end{array}$ \\
\hline & $\mathrm{x} 7$ & - & $\begin{array}{c}0.813^{* *} \\
(0.338) \\
\end{array}$ & - & - \\
\hline \multirow{2}{*}{$\begin{array}{l}\text { Socioeconomic } \\
\text { characteristic }\end{array}$} & gender & $\begin{array}{c}2.910^{* * * *} \\
(1.169)\end{array}$ & - & - & $\begin{array}{c}0.597^{* *} \\
(0.270)\end{array}$ \\
\hline & accident & - & - & - & $\begin{array}{c}-0.533^{* *} \\
(0.268)\end{array}$ \\
\hline Constant & constant & $\begin{array}{c}-6.731^{* * *} \\
(1.328)\end{array}$ & - & $\begin{array}{c}-2.329 * * * \\
(0.363)\end{array}$ & - \\
\hline
\end{tabular}


Table 5. Cont.

\begin{tabular}{|c|c|c|c|c|c|}
\hline \multirow{2}{*}{ Category } & \multirow{2}{*}{ Variable } & \multicolumn{2}{|c|}{ Non-Separated Sidewalk (M4) } & \multicolumn{2}{|c|}{ Separated Sidewalk (M5) } \\
\hline & & BL & OL & BL & $\mathrm{OL}$ \\
\hline \multirow{4}{*}{$\begin{array}{c}\text { Threshold } \\
\text { value }\end{array}$} & $\mu_{1}$ & - & $-0.551^{* * *}$ & - & $-3.584^{* * *}$ \\
\hline & $\mu_{2}$ & - & $1.351^{* * *}$ & - & $-0.697^{* * *}$ \\
\hline & $\mu_{3}$ & - & $5.625^{* * *}$ & - & $2.965 * * *$ \\
\hline & $\mu_{4}$ & - & - & - & $7.051^{* * *}$ \\
\hline \multirow{3}{*}{\multicolumn{2}{|c|}{$\begin{array}{c}\text { Sample size, } N \\
\text { Log likelihood } \\
\text { LR test }\end{array}$}} & 250 & 250 & 250 & 250 \\
\hline & & -23.041 & -246.295 & -95.41 & -216.404 \\
\hline & & $44.14^{* * *}$ & $86.01^{* * *}$ & $80.02 * * *$ & $107.46^{* * *}$ \\
\hline \multicolumn{2}{|c|}{ Pseudo $\mathrm{R}^{2}$} & 0.49 & 0.15 & 0.2954 & 0.199 \\
\hline \multicolumn{2}{|c|}{ AIC } & 56.083 & 508.590 & 200.823 & 450.808 \\
\hline \multicolumn{2}{|c|}{$\mathrm{BIC}$} & 73.690 & 536.761 & 218.430 & 482.501 \\
\hline
\end{tabular}

The modeling result shows that enforcement of illegal parking in commercial areas, segregation of vehicle traffic with pedestrians, expansion of existing sidewalk with green space, installation of additional signs, markings, or other facilities for pedestrians can help improve the pedestrian satisfaction. However, since land use patterns or illegal parking situations differ by areas, it is necessary to analyze further the effects of the factors identified in the overall model.

To identify whether the factors affecting pedestrian satisfaction vary according to land use, the survey data collected from four study areas were classified into two sub-datasets based on the land use, i.e., commercial area and residential area. As shown in Table 4, the variable of whether a sidewalk is separated or not (sidewalk) is commonly included in all the sub-models of M2 and M3. As with the M1 result, this indicates that vehicle-pedestrian segregation is a very important safety factor for pedestrian satisfaction. No other variables are in common among the M2 and M3 models.

For the commercial area models, overall satisfaction increases when pedestrians prefer walking convenience factors most to comfort or safety factors. Sufficient pedestrian guidance facilities (x3) and cleanliness of the street (x6) can also increase the level of satisfaction. In a comparison of the binomial model and ordered model for the commercial areas, the former has a larger number of significant variables, such as walking duration (walk60) and purpose (strip2), as well as respondent characteristics variables. Pedestrians whose average daily walking duration is ranging from 40 to $60 \mathrm{~min}$ tend to dissatisfy with their walking experience. This is mainly due to that $80 \%$ of the respondents from the commercial areas answered their average walking time is $60 \mathrm{~min}$ or less. Unlike the overall satisfaction model and the residential area models, walking in the commercial areas for shopping, leisure, and socializing activities increased satisfaction levels. For the socioeconomic background, males were satisfied more than females. In addition, pedestrians who are older and have lived in the city of Changwon for more than 20 years were also more satisfied. The reason why people who lived for a long period in the city have higher satisfaction seems to be due to their attachment to the area. On the other hand, it was found that for those who answered that they get along well with neighbors (neigh), their satisfaction decreased. Such people tend to perceive their residence space and surrounding area as a space for sharing with neighbors, whereas such sharing space is usually insufficient in commercial areas. Similar to this, for the people who use a car as a primary mode of transportation, walking can be regarded merely to serve a connecting function from/to the major mode and the origin or destination. Therefore, it can be seen that their walking satisfaction tends to be low.

In addition to land use, the effect on pedestrian satisfaction may differ depending on the street type and walking environment, i.e., separated sidewalk and illegal parking. According to whether or not separated sidewalks were installed, the sample data were reclassified into two sub-samples: non-separated sidewalk and separated sidewalk. Based on the field study, illegal parking existed only on the streets with non-separated sidewalks. 
As a result of examining factors for the case of non-separated sidewalks, the pedestrians who usually walk for a short time, i.e., less than $20 \mathrm{~min}$, and males tend to be more satisfied with their walking environment. Other factors that increase satisfaction include several convenience-related factors, including the sufficiency of walking space and pedestrian guidance facilities such as signs and markings, and convenient pavement materials. For the case of separated sidewalks, it was found that only the dummy variable of 'strip1' decreases the satisfaction when the walking purpose is commuting to work or school, or traveling for business. Among other factors related to convenience and comport attributes, the sufficient walking and green space $(x 1, x 5)$ and cleanliness of the street $(x 6)$ show the positive effects on pedestrian satisfaction.

\section{Conclusions}

A few studies have examined walkability or pedestrian satisfaction in South Korea, mainly the Seoul metropolitan area, but not in the smaller cities in the country. Thus, this study examines the factors affecting pedestrian satisfaction in Changwon, South Korea, concerning different aspects, i.e., land use and street type by modeling the survey data using binomial logit and ordered logit models to support urban design or transportation planning practitioners. With the whole sample, the binomial logit model showed a better fit than the ordered logit model. Of a total of 26 factors analyzed in this study, 20 of them had a positive effect on satisfaction, whereas the other six factors showed a negative effect. Nine factors representing the safety, convenience, and comfort attributes of walking are controllable through pedestrian policies. It is necessary for local governments or relevant authorities to establish appropriate policies aiming for improving facilities or enhancing maintenance for the positive factors, while for reducing the effects for the negative factors.

The modeling results for the different land use show that the physical environmental variables, such as separated sidewalk installation, can improve pedestrian satisfaction. Therefore, it is recommended to secure a sidewalk separated from a roadway when planning a new commercial or residential district and establishing relevant policies. Specifically, variables such as safety from traffic accidents and sufficient green space should be considered for residential areas. Pedestrian guidance facilities and cleanliness should be taken into account for commercial areas. In particular, the commercial-area model included the most factors, which is mainly because various people visit and engage in a variety of activities in such areas. For commercial areas, therefore, it is necessary to secure and expand walking and green space in order to not only improve the safety and convenience for pedestrians but also make the city more walkable and vitalize walking.

A common factor affecting the pedestrian satisfaction of streets with separated or non-separated sidewalks is also the sufficiency of walking space. This implies that the most impactful and urgent policy for pedestrians in Changwon is securing sidewalks or walking spaces. In addition, green space and cleanliness were significant in the nonseparated sidewalk case, whereas the sufficiency of pedestrian guidance facilities and sidewalk pavement condition were included in the separated sidewalk models. Therefore, it is recommended to reflect these different modeling results for the land use and street type when establishing pedestrian policies or allocating a budget.

There should be a caution to interpret or use the results of this study due to the following limitations. First, the survey data used in this study were initially collected mainly to support the policymakers of the city of Changwon. Therefore, a further study in the future should be conducted to validate whether any commonalities of the influencing factors on pedestrian satisfaction can be found in other areas. Although the spatial scope of this study is limited in Changwon, it is worth noting that the demographic structure by the age of the city is quite similar to that of Korea. In addition, most cities in the country, including Changwon, have been formed and evolved spontaneously since the Korean War so as to form the current urban street environments, e.g., non-separated sidewalks from vehicular traffic flows. These facts can enlarge the usefulness of the findings of this study, i.e., they can help urban design or transportation planning practitioners in the 
country. Second, the data were obtained in May 2018 before the COVID-19 pandemic. Although there has been no strict COVID-19 lockdown to restrict the travels of the public in South Korea, particularly in Changwon, the recent upheaval or restrictions might impact pedestrians' perception and make changes in their behaviors. For example, as people spend more time walking and cycling, the width of sidewalks has become a more important urban street design element. Many countries have expanded their walking infrastructure to provide minimum social distancing required and improve walkability [31,32]. Therefore, the COVID-19 pandemic might intensify the tendency that the sufficiency of walking space increases pedestrian satisfaction due to infection concerns or social distancing while walking. Future study needs to examine whether the findings are transferable after the pandemic. Lastly, even though the focus of the current study is not comparing the predictive power of both model types, it is recommended to examine the model validity by using a separated dataset in future studies.

Author Contributions: Conceptualization, S.L., M.H. and K.R.; methodology, S.L., M.H., K.R. and B.B.; formal analysis, S.L. and M.H.; validation, S.L., M.H., K.R. and B.B.; data curation, M.H.; writingoriginal draft preparation, S.L., M.H. and B.B.; writing-review and editing, S.L. and B.B.; supervision, M.H. and B.B. All authors have read and agreed to the published version of the manuscript.

Funding: This research received no external funding.

Institutional Review Board Statement: Not applicable.

Informed Consent Statement: Informed consent was obtained from all subjects involved in the study.

Data Availability Statement: The data presented in this study are available on request from the corresponding author. The data are not publicly available due to privacy.

Acknowledgments: This paper was prepared based on a part of the research work led mainly by the second author, titled "A Policy Study for Improving Pedestrian Transportation in Changwon". The report of the work with the same title was published by the Changwon Research Institute in 2018.

Conflicts of Interest: The authors declare no conflict of interest.

\section{References}

1. MOLTMA. Walkability Investigation and a Policy Index Development; Ministry of Land, Transport and Maritime Affairs: Gwacheon, Korea, 2011.

2. Litman, T.A. Economic Value of Walkability. Transp. Res. Rec. 2003, 1828, 3-11. [CrossRef]

3. Campisi, T.; Basbas, S.; Tesoriere, G.; Trouva, M.; Papas, T.; Mrak, I. How to Create Walking Friendly Cities. A Multi-Criteria Analysis of the Central Open Market Area of Rijeka. Sustainability 2020, 12, 9470. [CrossRef]

4. Sahani, R.; Bhuyan, P.K. Modelling Pedestrian Perspectives in Evaluating Satisfaction Levels of Urban Roadway Walking Facilities. Transp. Res. Procedia 2020, 48, 2262-2279. [CrossRef]

5. Rahimiashtiani, Z.; Ujang, N. Pedestrian Satisfaction with Aesthetic, Attractiveness and Pleasurability: Evaluating the Walkability of Chaharaghabbasi Street in Isfahan, Iran. Alam Cipta 2013, 6, 13-22.

6. Ewing, R.; Handy, S. Measuring the Unmeasurable: Urban Design Qualities Related to Walkability. J. Urban Des. 2009, 14, 65-84. [CrossRef]

7. Lee, W.D.; Ectors, W.; Bellemans, T.; Kochan, B.; Janssens, D.; Wets, G.; Choi, K.; Joh, C.-H. Investigating pedestrian walkability using a multitude of Seoul data sources. Transp. B Transp. Dyn. 2018, 6, 54-73. [CrossRef]

8. Kim, E.J.; Won, J.; Kim, J. Is Seoul Walkable? Assessing a Walkability Score and Examining Its Relationship with Pedestrian Satisfaction in Seoul, Korea. Sustainability 2019, 11, 6915. [CrossRef]

9. Zhang, J.; Tan, P.Y.; Zeng, H.; Zhang, Y. Walkability Assessment in a Rapidly Urbanizing City and Its Relationship with Residential Estate Value. Sustainability 2019, 11, 2205. [CrossRef]

10. Blečić, I.; Cecchini, A.; Congiu, T.; Fancello, G.; Talu, V.; Trunfio, G.A. Capability-wise walkability evaluation as an indicator of urban peripherality. Environ. Plan. B Urban Anal. City Sci. 2020, 48, 895-911. [CrossRef]

11. Distefano, N.; Pulvirenti, G.; Leonardi, S. Neighbourhood walkability: Elderly's priorities. Res. Transp. Bus. Manag. 2021, 40. [CrossRef]

12. Labdaoui, K.; Mazouz, S.; Acidi, A.; Cools, M.; Moeinaddini, M.; Teller, J. Utilizing thermal comfort and walking facilities to propose a comfort walkability index (CWI) at the neighbourhood level. Build. Environ. 2021, 193, 107627. [CrossRef]

13. Annunziata, A.; Garau, C. A Literature Review on Walkability and its Theoretical Framework. Emerging Perspectives for Research Developments. In Proceedings of the Computational Science and Its Applications-ICCSA 2020, Cham, Switzerland, 1-4 July 2020; pp. 422-437. 
14. Forsyth, A.N.N.; Southworth, M. Cities Afoot-Pedestrians, Walkability and Urban Design. J. Urban Des. 2008, 13, 1-3. [CrossRef]

15. Campisi, T.; Ignaccolo, M.; Inturri, G.; Tesoriere, G.; Torrisi, V. Evaluation of walkability and mobility requirements of visually impaired people in urban spaces. Res. Transp. Bus. Manag. 2021, 40. [CrossRef]

16. Lo, R.H. Walkability: What is it? J. Urban. Int. Res. Placemaking Urban Sustain. 2009, 2, 145-166. [CrossRef]

17. Ji, O.; Gu, Y. A Study on Satisfaction for Pedestrian Environment; Gyeonggi Research Institute: Suwon, Korea, 2008.

18. Sung, H.; Kim, T.; Kang, J. A Study on Evaluation of User Satisfaction for Walking Environment Planning Elements through Structural Equation Modeling. J. Korea Plan. Assoc. 2011, 46, 275-288.

19. Zainol, R.; Ahmad, F.; Nordin, N.A.; Aripin, A.W.M. Evaluation of users' satisfaction on pedestrian facilities using pair-wise comparison approach. IOP Conf. Ser. Earth Environ. Sci. 2014, 18. [CrossRef]

20. Mansouri, M.; Ujang, N. Tourist' expectation and satisfaction towards pedestrian networks in the historical district of Kuala Lumpur, Malaysia. Asian Geogr. 2016, 33, 35-55. [CrossRef]

21. Bellizzi, M.G.; Eboli, L.; Forciniti, C. Segregation vs interaction in the walkways: An analysis of pedestrians' perceptions. Res. Transp. Bus. Manag. 2019, 33. [CrossRef]

22. Bhaduri, E.; Bs, M.; Sen, J.; Maitra, B.; Goswami, A.K. Measuring User Satisfaction of Pedestrian Facilities and its Heterogeneity in Urban India-A Tale of Three Cities. J. East. Asia Soc. Transp. Stud. 2019, 13, 144-171. [CrossRef]

23. Arellana, J.; Saltarín, M.; Larrañaga, A.M.; Alvarez, V.; Henao, C.A. Urban walkability considering pedestrians' perceptions of the built environment: A 10-year review and a case study in a medium-sized city in Latin America. Transp. Rev. 2019, 40, 183-203. [CrossRef]

24. Oh, S.; Seo, S. Urban Policy Review for Pedestrian City; Architecture and Urban Research Institute: Anyang, Korea, 2013.

25. KOTI. The Improvement of Pedestrian Environment in Korea: Policies and Achievements; The Korea Transport Institute: Goyang, Korea, 2015.

26. Chung, K. Analysis of User Satisfaction for Walking Environment through Structural Equation Modeling at Traditional Markets. J. Reg. Assoc. Archit. Inst. Korea 2012, 14, 61-68.

27. Kim, S.H.; Lee, K.J.; Choi, K. A Study on Assessment Indicator of Walking Environment Considering Land Use Characteristics. J. Korean Soc. Civ. Eng. 2014, 34, 931-938. [CrossRef]

28. Moon, J.; Han, K.; Back, J.; Ban, Y. Analysis and Evaluation of Pedestrian Satisfaction using Survey Data. In Proceedings of the Conference of Korea Environmental Policy And Administration Society, Seoul, Korea, 25 February 2015; pp. $246-263$.

29. Yadav, J.S.; Jaiswal, A.; Nateriya, R. Modelling Pedestrian Overall Satisfaction Level at Signalised Intersection Crosswalks. Int. Res. J. Eng. Technol. 2015, 2, 2328-2337.

30. Moon, Y.; Kim, D.; Han, J.; Kang, J. A Study of Improvement on Pedestrian Level of Service by Pedestrian Satisfaction-Focused on Lower Floor Building Use in Seoul. J. Korean Soc. Civ. Eng. 2018, 38, 979-990. [CrossRef]

31. Zecca, C.; Gaglione, F.; Laing, R.; Gargiulo, C. Pedestrian routes and accessibility to urban services: An urban rhythmic analysis on people's behaviour before and during the COVID-19. TeMA J. Land Use Mobil. Environ. 2020, 13, 241-256. [CrossRef]

32. Paydar, M.; Kamani Fard, A. The Hierarchy of Walking Needs and the COVID-19 Pandemic. Int. J. Environ. Res. Public Health 2021, 18, 7461. [CrossRef] [PubMed] 